\title{
Pyrrhonian Skepticism Meets Speech-Act Theory
}

\author{
John Turri \\ University of Waterloo \\ john.turri@gmail.com
}

\begin{abstract}
This paper applies speech-act theory to craft a new response to Pyrrhonian skepticism and diagnose its appeal. Carefully distinguishing between different levels of language-use and noting their interrelations can help us identify a subtle mistake in a key Pyrrhonian argument.
\end{abstract}

\section{Keywords}

Pyrrhonism, skepticism, knowledge, belief, assertion, persuasion, speech acts

\section{Introduction}

Ever since J.L. Austin invented the modern subdiscipline of speech-act theory, there has been a tradition of speech-act theorists trying to solve philosophical problems - or to at least make progress toward solving them-by identifying mistakes made by philosophers who overlook important points about the practical import of language use. For example, Austin coined the phrase 'descriptive fallacy' for the mistake of treating language as if it were intended merely to describe things, when we actually use words to do much more than that (Austin 1962, 2-3, 100). John Searle identified the "speech-act fallacy," which is to mistake the purpose for which we typically use a term for part of the term's meaning (Searle 1969, 136-41). Searle also noted the "assertion fallacy," which is to confuse "the conditions for the performance of the speech act of assertion with the analysis of the meaning of particular words occurring in certain assertions" (Searle 1969, 141).

In this paper, I identify a similar mistake and propose that the appeal of Pyrrhonian skepticism is at least partly due to it. First I will present some basic distinctions at the heart of speech-act theory (section 2). Then I will present some revealing passages from Sextus Empiricus's Outlines of Pyrrhonism and offer an interpretation of the argument implicit therein (section 3). Finally I will 
argue that the Pyrrhonian argument commits a subtle error, which helps to satisfactorily explain its illusory appeal (section 4).

\section{A Taxonomy of Acts}

When you string together words in a way that satisfies the semantic and grammatical conventions of a particular language, you say something meaningful in that language. The act of saying something meaningful in a language is a linguistic act.

In performing a linguistic act, we often do further things. In uttering "I promise to send you comments on your paper," I promise to give you comments on your paper. In uttering "I emailed it to you this morning," you assert that you emailed it to me this morning. In uttering "I apologize for forgetting to send you comments," I apologize for forgetting to send you comments. A speech act is that which you do in performing a linguistic act. Promising, asserting, and apologizing are all speech acts.

We rarely perform speech acts for their own sake. We usually perform them to accomplish things. I beg you not to drive the icy road in order to convince you not to. If all goes well, I convince you by begging. I assert that the road is icy in order to persuade you that the road is icy. If all goes well, I persuade you by asserting. We usually make assertions in order to inform, alert or persuade others. A conversational act is the act of affecting your conversational partner by performing a speech act in a conversation. Begging and asserting are speech acts. Persuading, convincing, alerting and informing are conversational acts.

We perform a conversational act by performing a speech act, but the two are distinct. Consider what would happen if you weren't paying attention to me when I asserted that the road is icy: I would still have made the assertion, but I would not have informed you of the relevant fact. My informing you requires some uptake on your part, which may or may not be forthcoming. Likewise, consider what would happen if you didn't trust me or were presently in the grips of some wacky skeptical hypothesis. My assertion that the road is icy wouldn't persuade you that it's icy. My persuading you requires your cooperation, which again may or may not be forthcoming. ${ }^{1}$

\footnotetext{
1 The general picture of language sketched in this section derives ultimately from Austin (1962), through the lens of Fogelin and Sinnott-Armstrong (1997), ch. 1. This section draws on Turri (2010).
} 
Not all conversational acts are created equal. Informing and alerting are easy. They require the least amount of uptake or cooperation from an interlocutor. For me to inform or alert you that Q, you need only understand that I've told you that Q. Normally this happens automatically and involuntarily. Persuasion is harder — potentially much harder. To persuade you, I must not only inform you, but my assertion must cause you to believe Q. ${ }^{2}$ Often times persuasion requires no more than informing because our default mode is one of credulity, though this is of course highly defeasible and subject to many qualifications (Reid 1764, 6.24). But sometimes persuading requires more than merely informing. You might want or need more evidence before you believe Q, and if my goal is to persuade you, that makes my job harder. You might even be neurotically or psychotically bent on scrutinizing the evidence for everything I say. If my goal is to persuade, that makes my job extremely difficult and perhaps even impossible.

The three-fold distinction among linguistic, speech and conversational acts is standard and sufficient for present purposes. But it suffers from an apparent weakness. The three-fold distinction ought to be at least four-fold. The category of conversational acts conceals radical diversity. I distinguished between easy and hard conversational acts, but it seems to be a difference in kind rather than degree. Informing stands to persuading as asserting to informing, and as uttering to asserting. You assert by uttering, inform by asserting, and persuade by informing. True, you can perform one speech act by performing another, as when in a courtroom you swear by asserting, so there is no absolute prohibition on the by-relation relating two distinct acts within the same category. But the gap between informing and persuading, or between warning and dissuading, is potentially vast and challenging, whereas nothing similar is true of swearing by asserting when under oath. Indeed, the latter is automatic.

We can account for this difference by distinguishing a further type of language act. A dialectical act is the act of affecting your conversational partner by performing a conversational act. Persuading, dissuading, encouraging and discouraging are dialectical acts. The division between conversational and dialectical acts isn't essential for present purposes. I could make all my points equally well without it. But the division seems right, so it's worth mentioning it explicitly. ${ }^{3}$

2 The causation must be non-deviant too, but I set that issue aside here.

3 What I say here is perfectly consistent with Austin's own original views on the subject, for he says that he identified "three, if not more" uses of language (Austin 1962, 108), and noted how difficult it was to draw a bright line between uses of language proper and "mere" consequences of language use (Austin 1962, 102). Searle (1969, ch. 2) identifies yet another type of act, 


\section{The Pyrrhonian Way}

According to Sextus Empiricus, Pyrrhonian skeptics ('Pyrrhonists' for short) aim to achieve tranquility through suspending judgment on all propositions, except for those pertaining to how things appear to them presently. ${ }^{4}$ Call these the "non-evident propositions." Pyrrhonists are able to suspend judgment on a non-evident proposition by employing methods or "modes" of "opposition," which involve marshaling considerations for and against the proposition, in such a way that the case for and against are "equally convincing." Suspension of judgment, and thereby tranquility, follows as the natural result. ${ }^{5}$

It isn't entirely clear whether Pyrrhonists think that suspension of judgment is something that they ought to do, in some normatively significant sense of 'ought'. Sometimes it seems as if Sextus is merely reporting what the Pyrrhonist doesn't find convincing, and the psychological process involved in reaching a state of suspension. Other times it seems as if Sextus is claiming that suspension of judgment is what we ought to do, either because it will promote a better outcome, or because the total evidence supports neither affirming nor denying the proposition in question. Of course, it could be a combination of the descriptive and normative. But I will not try to settle the question of what exactly Sextus and other Pyrrhonists intended. I take it as obvious that Sextus's discussion at least strongly suggests that, in a distinctively intellectual or epistemic sense of 'ought', we ought to suspend judgment on non-evident propositions. ${ }^{6}$ I trust that anyone who has closely studied the work will grant this as a fair assessment. This assessment is corroborated by the fact that many

the "propositional acts" of referring and predicating, interposed between linguistic and speech acts. I'll have nothing to say about propositional acts here, except to note that they could unproblematically be added to my taxonomy.

4 "We do not overturn anything which leads us, without our willing it, to assent in accordance with a passive appearance - and these things are precisely what is apparent" (Outlines of Pyrhhonism I 19 (i.e. Book I, paragraph 19); hereafter cited as ' $P H$ '). All translations are from the Annas and Barnes edition of $\mathrm{PH}$.

${ }^{5}$ Sextus puts it this way: "Scepticism is an ability to set out oppositions among things which appear and are thought of in any way at all, an ability by which, because of the equipollence in the opposed objects and accounts, we come first to suspension of judgment and afterwards to tranquility. ... By 'opposed accounts' we do not necessarily have in mind affirmation and negation, but take the phrase simply in the sense of 'conflicting accounts'. By 'equipollence' we mean equality with regard to being convincing or unconvincing: none of the conflicting accounts takes precedence over any other as being more convincing. Suspension of judgment is a standstill of the intellect, owing to which we neither reject nor posit anything. Tranquility is freedom from disturbance or calmess of soul" (PH I 8, 10).

${ }^{6}$ Compare Perin (2010), but also see Williams (1988). 
thinkers have taken Pyrrhonian arguments to establish that conclusion, or to at least modestly support it, enough so that it calls for a substantial response (e.g. Fogelin 1994, Sinnott-Armstrong 2004, Klein 2005, Sosa 2007).

In his Outlines of Pyrrhonism, Sextus Empiricus famously details three mutually supportive modes: infinite regress, hypothesis, and reciprocity (PH I 165). The deployment of these three modes is widely known as "Agrippa's Trilemma" (Williams 1999). In the mode of infinite regress, the Pyrrhonist asks us what our "source of conviction" is for the matter in question, and when we produce it, he asks us what our source of conviction is for that, and so on ad infinitum, "so that we have no point from which to begin to establish anything, and suspension of judgment follows." In the mode of reciprocity, we accept the challenge to keep citing sources of conviction, but we don't keep finding new sources. Instead at some point we cite the original source in support of one of the subsequent sources. The Pyrrhonist rejects this because if the subsequent source serves as a basis for the original source, then the original source cannot in turn properly serve as a basis for the subsequent source. Thus the mode of reciprocity might just as well be called the mode of circularity. But suppose that at some point we resist the challenge to produce a further source, and we don't lapse into circularity. Instead we "claim to assume [something] simply and without proof." That is, we simply hypothesize that something is true, and proceed with our demonstration from that point. This is the mode of hypothesis. The Pyrrhonist isn't satisfied with mere hypothesis, for reasons that we will discuss in greater detail shortly.

The three patterns of reasoning identified in Agrippa's Trilemma exhaust the logical alternatives and correspond roughly to the modern positions of infinitism, foundationalism and coherentism (Fogelin 1994, ch. 6; Williams 1999; Klein 1999). Infinitism is the view that an infinite and non-repeating series of reasons can properly convince; foundationalism is the view that finite and non-repeating series of reasons can properly convince; coherentism is the view that circular series of reasons can properly convince. None of the patterns convinces Pyrrhonists, so they suspend judgment.

The Agrippan Trilemma recurs repeatedly in the Outlines. The Pyrrhonist relies on it heavily. Here are three representative passages to anchor our discussion.

There is a dispute among the Dogmatists; for some say that some things are true, and some that nothing is true. And it is not possible to decide the dispute; for if you say that some things are true, you will not be found convincing if you say it without proof, because of the dispute; and if you actually want to bring a proof, then if you confess that the proof is false you will be unconvincing, while if you say that the proof is true you fall into the reciprocal arguing and in addition you will be asked for a proof of the fact that it is true-and another proof for that, 
and so ad infinitum: and it is impossible to prove infinitely many things. Therefore it is impossible to know that some things are true. ( $\mathrm{PH}$ II 85)

There has been a dispute among our predecessors, some saying that there are indicative signs, others asserting that nothing is an indicative sign. Now anyone who says that there are indicative signs will speak either simply and without proof, making a mere assertion, or else with proof. But if he makes a mere assertion he will be unconvincing; and if he wants to give a proof he will take for granted the matter under investigation. For since proof is said to be a species of sign, then as it is controversial whether there are any signs or not, there will be controversy too as to whether there are any proofs or not... But it is absurd to try to prove what is under investigation through what is equally under investigation or through itself; therefore no-one will be able by way of a proof to affirm that there are signs. But if it is not possible to make a firm assertion about signs either simply or with a proof, it is impossible to make an apprehensive assertion about them[.] (PH II 121)

Since some say that the senses are affected vacuously (for none of the things they seem to grasp exist), while others assert that everything by which they think they are moved exists, and yet others that some of these things exist and some do not exist, we shall not know to whom to give our assent. For we shall not decide the dispute with the senses (since we are investigating whether they are affected vacuously or truly apprehend things), nor yet with anything else (for there is no other standard through which we should judge, according to the hypothesis before us). It will therefore be undecidable and inapprehensible whether the senses are affected vacuously or apprehend something; from which it follows that we must not attend to the senses alone in judging objects-for we cannot say of them whether they apprehend anything at all. (PH II 49)

Three interrelated themes emerge from these passages: knowledge, assertion, and persuasion (i.e. convincing). Various connections are explicitly claimed or strongly suggested among them. But how might this all fit together into a proper argument with a skeptical upshot?

I submit that something like the following argument lurks just below the surface. Let 'it' stand for any non-evident proposition of the sort we'd ordinarily take ourselves to know, 'them' name the target audience, 'may' designate epistemic permission, and 'can' designate ability in a normal environment.

The Pyrrhonian Argument

1. If I know it, then I may assert it. (Premise)

2. If I may assert it, then I can persuade them. (Premise)

3. So if I know it, then I can persuade them. (From 1-2)

4. But I can't persuade them. (Premise)

5. So I don't know it. (From 3-4)

Instead of "persuade them" we could have said "prove it to their satisfaction," because persuading the Pyrrhonists is practically the same thing as proving it to their satisfaction. 
The argument is valid, so non-skeptics are left to contest one or more premises. It turns out that their options are limited. Let's take Pyrrhonists at their word when they say that line 4 is true. So since line 5 follows validly from lines 3 and 4, line 3 comes in for suspicion. But line 3 follows validly from lines 1 and 2 , so rejecting 3 requires rejecting at least one of those two.

If Pyrrhonists accepted line 1, as Sextus's discussion appears to indicate, then they were early proponents of something very close to the knowledge account of assertion, as it has come to be called. The knowledge account of assertion says that knowledge is the epistemic status that licenses assertion: on one formulation, you may assert Q if and only if you know that Q (DeRose 2002; Hawthorne 2004, 23 n. 58; see also Williamson 2000 and Turri 2011). When you assert something you don't know, the assertion fails epistemically. Interestingly, Sextus's discussion also strongly suggests that Pyrrhonists accepted a knowledge account of belief, which is the view that knowledge is the epistemic status that licenses belief: you may believe Q if and only if you know that Q (Williamson 2000, Sutton 2007; see Conee 2007 for critical discussion). When you believe something you don't know, the belief fails epistemically. ${ }^{7}$

But the knowledge account of assertion is controversial (as is the knowledge account of belief). Many philosophers think it is deeply mistaken (e.g. Douven 2006, Lackey 2007, Kvanvig 2009). And I doubt that the allure of Pyrrhonian skepticism is confined to those who accept the knowledge account. Fortunately we can effectively run the argument without it. Even philosophers who reject the knowledge account still think that there is some non-trivial positive

\footnotetext{
7 Perhaps Pyrrhonists didn't accept a fully general knowledge account of belief. They distinguish between unreflective and automatic acceptance of propositions on the one hand, and reflective and voluntary acceptance on the other (e.g. PH I 19-24). Call the former unreflective belief and the latter reflective belief. Unreflective beliefs include, for example, the belief that I am hungry (upon experiencing hunger pangs), and the belief that a predator approaches (upon seeing a panther approach). Reflective beliefs include theoretical claims about causation, the nature of persons, the hidden structure of matter, etc. Sextus sometimes claims that Pyrrhonian arguments apply only to reflective belief, sparing unreflective belief from their critical gaze because it's out of our control, forced on us by our nature or upbringing. Given all this, Pyrrhonists might accept a knowledge account of reflective belief, but not unreflective belief. At the same time, however, Sextus also says that Pyrrhonists "assent without opinion to what" is found convincing in "everyday life" (PH II 102), and that they "live by experience and without opinions, in accordance with the common observations and preconceptions" (PH II 246). In light of these remarks, we might conclude that Pyrrhonists did accept a knowledge account of unreflective belief too, since they claim to be without opinion on such matters, letting experience and custom guide their behavior directly. After all, why would they suspend judgment if belief were indeed appropriate? But this is a vexed interpretative question which falls outside this paper's central focus, so I'll leave the matter there.
} 
epistemic status that a proposition must have in order for you to properly assert it. That is, they still think there is some significant epistemic relation, such as its being reasonable or justified for you, which licenses assertion. ${ }^{8}$ Assertions that lack the relevant positive epistemic status fail, whatever that status is. To forestall objections from this quarter, we could run a more generic version of the argument:

$1^{\prime}$. If it has positive epistemic status for me, then I may assert it.

2. If I may assert it, then I can persuade them. (Premise)

$3^{\prime}$. So if it has positive epistemic status for me, then I can persuade them. (From 1', 2)

4. But I can't persuade them. (Premise)

5'. So it doesn't have positive epistemic status for me. (From 3', 4)

$5^{\prime}$ is actually a stronger skeptical conclusion than 5, because knowing a proposition entails that it has positive epistemic status for you, whereas the converse intuitively isn't true, for it could have some positive status for you that falls short of knowledge, as with Gettier cases or false justified beliefs. The upshot, then, is that virtually everyone can find a version of the argument whose first line satisfies them. So the argument's first premise seems to be safe. For convenience, however, I will continue speaking as if the knowledge account were true, and trust that readers will substitute their preferred epistemic norm at appropriate junctures.

That leaves only line 2. Why think that if I may assert some proposition, then I can persuade my audience? Or to put the question conversely, why think that if I can't prove it to my audience's satisfaction, then I may not assert it? Why think that the inability to persuade indicates an epistemic failure?

\section{The Error of Their Way}

One challenge would be to prove that line 2 of the Pyrrhonian Argument is false. That's not my goal here. I'm confident that it is false and I'd like an explanation of why someone might nevertheless be attracted to it. In a word, I'd like to help explain its illusory but nevertheless real appeal.

Let's start by considering Michael Williams's influential diagnosis of Pyrrhonian skepticism, to which I will compare my own proposal. I have much sympathy when Williams writes, "Sceptical arguments can go wrong without being susceptible to direct refutation. We may learn most from scepticism by

\footnotetext{
${ }^{8}$ David Sosa (2009) is an exception.
} 
approaching it in a more roundabout, diagnostic way" (2001, 248). Likewise I'm sympathetic when Williams writes, "Agrippan skepticism is supposed to be intuitive," depending only on considerations that appear plausible from the perspective of our ordinary assessment of knowledge claims (2001, 153). But I'm not entirely convinced by Williams's ultimate verdict on Pyrrhonian skepticism, which is that it is unnatural and "not intuitive at all" $(2001,153)$.

Williams accuses the Pyrrhonist of "taking for granted" the "Prior Grounding Requirement" model of knowledge. Indeed, Williams claims that this requirement "must be presupposed by the Agrippan argument" $(2001,147)$. The requirement comprises four principles:

PG1. No Free Lunch Principle. Epistemic entitlement ... does not just accrue to us: it must be earned by epistemically responsible behavior.

PG2. Priority Principle. It is never epistemically responsible to believe a proposition true when one's grounds for believing it true are less than adequate.

PG3. Evidentialism. Grounds are evidence: propositions that count in favour of the truth of the proposition believed.

PG4. Possession Principle. For a person's belief to be adequately grounded, it is not sufficient for there merely to be appropriate evidence for it. Rather, the believer himself or herself must possess (and make proper use of) evidence that makes the proposition believed (very) likely to be true.

When taken together, these principles supposedly entail that "no belief is responsibly held unless it rests on adequate and citable evidence" $(2001,148)$. Call this the Citation Principle. The Citation Principle could be taken to motivate line 2 of the Pyrrhonian Argument. To see this, suppose that positive epistemic status consists in properly basing your belief on adequate and citable evidence. If the evidence is adequate and citable, then you could cite it in an effective proof. This brings us very close to line 2 of the Pyrrhonian Argument. I take this to be a virtue of Williams's treatment of Pyrrhonism. An effective critique of the Citation Principle might then serve as a therapeutic diagnosis of Pyrrhonism's appeal. ${ }^{\text {? }}$

9 The Citation Principle comes in for scrutiny in G.E. Moore's famous proof of an external world (1939). "I can know things, which I cannot prove," says Moore. For example, "I have, no doubt, conclusive evidence that I am awake; but that is a very different thing from being able to prove it. I could not tell you what all my evidence is; and I should require to do this at least, in order to give you a proof." What's more, Moore adds, "I do not believe that any proof is possible in nearly all cases" $(1939,148)$. 
Williams might be right that Pyrrhonists take the Prior Grounding Requirement for granted. But it doesn't seem like Pyrrhonists must do that, and I doubt that it's the whole story because it can't smoothly explain Pyrrhonism's appeal. The four principles don't seem all that intuitive. And it's not clear how deeply embedded they are in our ordinary practice because, as G.E. Moore (1939) pointed out, we do ordinarily accept that people know many things, even though they aren't able to prove them. How might you prove, for example, that you feel pressure on your arm, or that you were thinking of your grandmother just a moment ago? Or consider a scene from Robert Louis Stevenson's The Strange Case of Dr. Jekyll and Mr. Hyde. A shaken and ill Jekyll tells his friend Utterson that Mr. Hyde "will never more be heard of." When Utterson suggests—rightly, it turns out, as the story unfolds-that Jekyll's assertion might not be entirely warranted, Jekyll replies, "I have grounds for certainty that I cannot share with anyone." ${ }^{10}$ Jekyll doesn't simply mean that prudence forbids sharing his grounds, although that is also true, since revealing his relation to Hyde would be disastrous to Jekyll personally. Jekyll also means that he is simply incapable of sharing (at least some of) his evidence, a reading confirmed later when Jekyll writes that his transformational experiences were marked by "indescribably new" sensations. ${ }^{11}$ Jekyll's evidence is beyond words, and so defies the Citation Principle. But the storyline does not baffle the reader, as might be expected if the Prior Grounding Requirement were grounded in our ordinary practice.

So I think it would be good to have another explanation of Pyrrhonism's appeal, one that doesn't diagnose it as the result of well-hidden but implausible abstract theoretical assumptions. Such an alternative explanation needn't conflict with Williams's. It could be complementary.

I submit that line 2 could seem true because we conflate two types of normatively significant failure: instrumental and epistemic. On the one hand, if we fail to achieve our goal in asserting, then the assertion is an instrumental failure. Failing to achieve our goal is bad. ${ }^{12}$ On the other hand, if we fail to satisfy the epistemic norms licensing assertion, then the assertion is an epistemic or intellectual failure. It is also a social failure because we breach trust by giving others our word when we lack the authority. Intellectual and social failures are bad.

Why might we make this mistake when it comes to assertion? Our earlier reflections on language-use will now pay dividends. We noted that we

\footnotetext{
10 In the section "Incident of the Letter."

11 In the section "Henry Jekyll's Full Statement of the Case."

12 The badness here is pro tanto, of course. All things considered, it might be good that we fail, especially if our goals are bad.
} 
typically perform speech acts in order to perform conversational and dialectical acts. For instance, we typically assert something to someone in order to inform and thereby persuade them of its truth. If all goes well, they believe us, and come to know the proposition based on our testimony. But if things don't go well and we fail to prove it to their satisfaction, then our assertion has, in an important sense, failed. We have failed to perform the relevant conversational or dialectical act. We might easily mistake the assertion's instrumental failure for an intellectual failure in making the assertion. But it isn't automatically an intellectual failure. The assertion, qua assertion, might be perfectly fine, even though the assertion, qua persuasive device, is a complete failure.

The dialectical fallacy is to mistake the requirements of successfully performing a dialectical act for norms governing the speech act by which we typically perform the dialectical act. My proposal, then, is that people find line 2 of the Pyrrhonian Argument plausible because we assert in order to persuade, and the dialectical fallacy is easy to commit.

My proposal has several virtues. First, it's predicated on the naturalness of a simple but subtle mistake that we might make in the ebb and flow of an ordinary conversation or when imagining engaging the skeptic, and which might not become apparent without considerable reflection on the nature of language-use and the epistemic requirements of speech acts. This is a more likely candidate for explaining line 2's appeal than positing an implicit reliance on highly theoretical, contentious, and ultimately counterintuitive principles about the relationship between knowledge and evidence.

Second, and as a result, my proposal seems well positioned to explain the enduring and widespread appeal of Pyrrhonian skepticism, and the Agrippan modes in particular, since people from all different times, places and cultures regularly engage in assertion and persuasion. By contrast, it's not obvious that such a variety of people are all unwittingly and implicitly accepting the Prior Grounding Requirement and Citation Principle.

Third, my proposal helps provide a perfectly general explanation of Pyrrhonism's appeal. Assertion and persuasion range over all the propositions we're concerned with. That is, any proposition up for consideration can be asserted, and we can try to persuade others of it too. The perfect generality of assertion and persuasion suit them well for Pyrrhonian purposes, because the Agrippan mode can thus be used to incite doubt about any proposition at all (compare Pritchard 2000, 201). By focusing on the general relation between assertion and persuasion, my proposal can thus explain Pyrrhonism's appeal across the wide range of subject matters for which it's employed to similar effect.

It might be objected that I can't simply help myself to such a neat distinction between instrumental and epistemic failure. It might be granted that the two are distinct, since epistemic failure can occur without instrumental failure, as 
frequently happens when one person persuades another by lying. But for all I've said, the objection continues, instrumental failure might nevertheless suffice for epistemic failure. And sufficiency is really all that is needed for the Pyrrhonist to hold his ground.

In response, instrumental failure does not suffice for epistemic failure. Sometimes we enter what I call advisory mode, where we make it clear that we're advising our audience on the matter, and this will take the form of making the relevant assertions, thereby informing them, and nothing more. We aim to persuade, but not if it requires anything more than the minimal effort. There are conventional mechanisms to, as John Hawthorne puts it, "restructure a conversation" (Hawthorne 2004, 24 n. 59). One such restructuring is to move from one where challenges and questions are appropriate, what we might call egalitarian mode, into advisory mode. In an uncompromising, matter-of-fact tone, we might say any of the following:

- Look, here is the way things are ...

- Listen, I'm not arguing with you, I'm telling you...

- I'm not the least bit interested in debating the point, but you should know that...

Examples of this are easy to find. Consider this passage from H.G. Wells's The Time Machine.

Time Traveller: You have told Bland, and Dash, and Chose about the machine?

The Editor: But the thing's a mere paradox.

Time Traveller: I can't argue tonight. I don't mind telling you the story, but I can't argue. I will tell you the story of what has happened to me, if you like, but you must refrain from interruptions. I want to tell it. Badly. Most of it will sound like lying. So be it! It's true - every word of it, all the same.

Notice that Editor's professed skepticism is a natural trigger for Time Traveler to enter advisory mode. When someone indicates that they'll be hard to persuade, it's unsurprising that we might not wish to invest ourselves too much in trying to persuade them. ${ }^{13}$

\footnotetext{
13 Related to advisory mode is that commonplace retort, "Hey, I'm just saying." This might be another way of flagging that we're not going to do anything more than simply assert the proposition in question for our audience's benefit. Unger (1975), 267 n. 7 suggests a different, and I think mistaken, view of saying.
} 
Closely related to advisory mode is didactic mode, where we make it clear that we aim merely to inform, with no suggestion that persuasion is something we expect or desire, or that we're the least bit interested in proving the point or otherwise explaining the grounds for our assertion. In an appropriately unconcerned or even disdainful tone, we might say something like:

- I don't expect you to believe me-in fact I don't even care whether you do-but it's my duty to inform you ...

By entering the advisory or didactic mode, we disengage from some of the typical expectations and burdens of conversation. Call such assertions disengaged or unencumbered assertions, contrasting them with ordinary engaged or encumbered assertions. We feel no pressure to automatically regard unpersuasive disengaged assertions as epistemic failures. ${ }^{14}$ In some cases, we even expect them to be unpersuasive, and we regard this not as a failure of ours, but of our audience's. Thus instrumental failure does not plausibly suffice for epistemic failure. So the envisioned objection fails.

Pyrrhonists made a distinction related to the distinction just made between engaged and disengaged assertion. They distinguished between "strong" or "firm" assertion on the one hand, and "weak" or "mere" assertion on the other (see esp. PH II 95, 107, 121, 123). A strong assertion is one for which the speaker is willing to attempt a proof in support of it. A mere assertion is one made "simply and without proof" (PH II 121). For example, Sextus notes, "When the Stoics say that there are sayables, they either make a mere assertion or else use a proof" (PH II 107). And from a passage quoted earlier, "Anyone who says that there are indicative signs will speak either simply and without proof, making a mere assertion, or else with proof. But if he makes a mere assertion he will be unconvincing." Yet as we have seen, whereas Pyrrhonists might have us conclude that a mere assertion epistemically fails because it is unconvincing, it needn't work that way. A disengaged assertion needn't be epistemically weak or count as an epistemic failure, regardless of how it fares dialectically.

${ }^{14}$ Compare Searle (1969), 67. Regarding assert, state, affirm and the like, Searle says, "Unlike argue these do not seem to be essentially tied to attempting to convince. Thus 'I am simply stating that $p$ and not attempting to convince you' is acceptable, but 'I am arguing that $p$ and not attempting to convince you' sounds inconsistent." Searle's first point here (about stating) is right in line with the points I make in the main text. But the second point (about arguing) doesn't seem right. Just as I might regard it as my duty to inform you of something but be unconcerned with whether you're persuaded, likewise I might regard it as my duty to present you with an argument, but disavow any intention of actually persuading you by presenting it to you. 
It might also be objected that the ancient Pyrrhonist wouldn't accept line 2 of the Pyrrhonian Argument. ${ }^{15}$ That is, it might be questioned whether the ancient Pyrrhonists would really accept that if I may assert it, then I can persuade them, and so, conversely, that if I can't persuade, then I may not assert. In response, I point to a striking passage in PH II 85, quoted earlier. For convenience, here is the relevant passage again.

There is a dispute among the Dogmatists; for some say that some things are true, and some that nothing is true. And it is not possible to decide the dispute; for if you say that some things are true, you will not be found convincing if you say it without proof, because of the dispute; and if you actually want to bring a proof, then if you confess that the proof is false you will be unconvincing, while if you say that the proof is true you fall into the reciprocal argument and in addition you will be asked for a proof of the fact that it is true — and another proof for that, and so ad infinitum: and it is impossible to prove infinitely many things. Therefore it is impossible to know that some things are true. ( $P H$ II 85)

The conclusion in this passage is that it is impossible to know that some things are true, and the reason given for this conclusion is that you can't decide the dispute about whether some things are true. So the basic argument is (where 'Q' abbreviates 'some things are true'):

You can't decide the dispute whether Q. And if you can't decide the dispute, then you can't know. So you can't know whether $\mathrm{Q}$.

Sextus explains precisely why you can't decide the dispute. He appears to reason as follows:

To decide the dispute whether Q, you must be persuasive. To be persuasive, you must say whether Q. To say whether Q, you must say so with proof or without proof. But if you say so without proof, then you won't be persuasive; and if you say so with proof, then you won't be persuasive. So either way, you won't be persuasive. So you can't decide the dispute.

The inability to persuade entails that you can't decide the dispute, and the inability to decide the dispute entails that you can't know. So the inability to persuade entails that you can't know. So if knowledge is the norm of assertion, then the ancient Pyrrhonist seems committed to the claim that if you can't persuade, then you may not assert, which is equivalent to the claim that if you may assert, then you can persuade. And this just is line 2 of the Pyrrhonian Argument.

15 Thanks to Diego Machuca for raising the objection. 


\section{Conclusion}

Pyrrhonian skepticism can easily seem natural and intuitive. The best sort of diagnosis will help us understand both why it seems natural and intuitive, and why it's nevertheless false. I have argued that speech-act theory provides us with the resources to make a diagnosis of just this sort. ${ }^{16}$

\section{References}

Austin, J.L. (1962). How to Do Things with Words. Oxford: Oxford University Press.

Conee, E. (2007). Review of Jonathan Sutton's Without Justification. Notre Dame Philosophical Reviews. <http://ndpr.nd.edu/review.cfm?id=11803>

DeRose, K. (2002). “Assertion, Knowledge and Context," Philosophical Review 111: $167-203$.

Douven, I. (2006). "Assertion, Knowledge, and Rational Credibility.” Philosophical Review 115: 449-85.

Fogelin, R.J. (1994). Pyrrhonian Reflections on Knowledge and Justification. Oxford: Oxford University Press.

Fogelin, R.J. \& Sinnott-Armstrong, W. (1997). Understanding Arguments: An Introduction to Informal Logic. New York: Harcourt Brace.

Klein, P. (1999). "Human Knowledge and the Infinite Regress of Reasons," Philosophical Perspectives 13: 297-325.

. (2005). "Infinitism is the Solution to the Regress Problem," 131-40 in M. Steup \& E. Sosa (eds.), Contemporary Debates in Epistemology. Malden, Mass.: Blackwell.

Kvanvig, J.L. (2009). "Assertion, Knowledge, and Lotteries," 140-60 in D. Pritchard \& P. Greenough (eds.), Williamson on Knowledge. Oxford: Oxford University Press.

Lackey, J. (2007). "Norms of Assertion,” Noûs 41: 594-626.

Moore, G.E. (1939). "Proof of an External World," reprinted in Philosophical Papers. New York: Collier Books, 1959.

Perin, C. (2010). The Demands of Reason: An Essay on Pyrrhonian Scepticism. Oxford: Oxford University Press.

Pritchard, D. (2000). "Doubt Undogmatized: Pyrrhonian Scepticism, Epistemological Externalism, and the 'Metaepistemological' Challenge," Principia-Revista Internacional de Epistemologia 4: 187-214.

Reid, T. (1764). An Inquiry into the Human Mind on the Principles of Common Sense. Edited by , D.R. Brookes. University Park, Penn.: Pennsylvania State University, 1997.

Searle, J.R. (1969). Speech Acts: An Essay in the Philosophy of Language. Cambridge: Cambridge University Press.

Sinnott-Armstrong, W. (2004). “Classy Pyrrhonism,” 188-207 in W. Sinnott-Armstrong (ed.), Pyrrhonian Skepticism. Oxford: Oxford University Press.

${ }^{16}$ For helpful conversation and feedback, I happily thank Matt Benton, E.J. Coffman, Christian Hegele, Diego Machuca, Duncan Pritchard, Angelo Turri, and an anonymous referee. This research was supported by the Social Sciences and Humanities Research Council of Canada. 
Sosa, D. (2009). "Dubious Assertions,” Philosophical Studies 146: 269-72.

Sosa, E. (2007). A Virtue Epistemology: Apt Belief and Reflective Knowledge, Volume 1. Oxford: Oxford University Press.

Stevenson, R.L. (1886). The Strange Case of Dr. Jekyll and Mr. Hyde. New York: Barnes and Noble Classics, 2004.

Turri, J. (2010). "Epistemic Invariantism and Speech Act Contextualism," Philosophical Review 119: 77-95.

. (2011). "The Express Knowledge Account of Assertion," Australasian Journal of Philosophy 89: $37-45$.

Unger, P. (1975). Ignorance: A Case for Skepticism. Oxford: Oxford University Press.

Wells, H.G. (1895). The Time Machine. New York: Signet, 2002.

Williams, M. (1988). "Skepticism Without Theory," Review of Metaphysics 41: 547-88. . (1999). "Skepticism," 35-69 in J. Greco \& E. Sosa (eds.), The Blackwell Guide to Contemporary Epistemology. Malden, Mass.: Blackwell.

(2001). Problems of Knowledge: A Critical Introduction to Epistemology. Oxford: Oxford University Press.

Williamson, T. (2000). Knowledge and Its Limits. Oxford: Oxford University Press 